\title{
Comparative Clinical Evaluation of Platelet Rich Fibrin and Subepithelial Connective Tissue Graft in Interdental Papilla Reconstruction: A Randomized Controlled Clinical Trial
}

Isha Goyal, Nishi Tanwar, Shikha Tewari, Rajinder Kumar Sharma, and Satish Chander Narula

\section{ABSTRACT}

Background: Aesthetics has become a major concern nowadays. Loss of
interdental papilla in the anterior region of the oral cavity accounts for a
major compromise in aesthetics. Thus, techniques to correct this defect has
emerged as a new area of research in dentistry. The present study aims to
compare reconstruction of the interdental papilla using subepithelial
connective tissue graft (SCTG)and platelet rich fibrin (PRF).

Material and Methods: The present randomised clinical trial included 36 patients equally divided into test (platelet rich fibrin) and control groups (subepithelial connective tissue graft). Papilla reconstruction was done and clinical parameters- contact point to interdental papilla distance (CPID), width of keratinized gingiva (WKG), plaque index (PI), gingival index (GI), papillary bleeding index (PBI), pocket depth (PPD) were recorded at baseline, 3 and 6 months. Healing index (HI) was recorded at 1, 2 and 3 weeks.

Results: At the end of 6 months, it was found that interdental papillae fill in terms of decrease in distance from the contact point to the interdental papilla tip and gain in WKG was statistically significant in both the groups ( $p$ value $\leq \mathbf{0 . 0 5}$ ). On intergroup comparison, however, it was found that the improvement in the abovementioned parameters was significantly greater in the control group (39.32\%) as compared to the test group (14.79\%). The difference in other clinical parameters at various time intervals were found to be nonsignificant.

Keywords: Connective tissue; Gingiva; Plastic surgery.
Published Online: September 09, 2021

ISSN: $2684-4443$

DOI: $10.24018 /$ ejdent.2021.2.5.90

\section{Isha Goyal}

Post Graduate Institute of Dental Sciences, Rohtak, Haryana, India.

(e-mail: goyalisha05@gmail.com) Nishi Tanwar*

Post Graduate Institute of Dental Sciences, Rohtak, Haryana, India.

(e-mail: nsh_tanwar@yahoo.co.in) Shikha Tewari

Post Graduate Institute of Dental Sciences, Rohtak, Haryana, India.

(e-mail: drshikhatewari@ yahoo.com) Rajinder Kumar Sharma

Post Graduate Institute of Dental Sciences, Rohtak, Haryana, India.

(e-mail: rksharmamds@yahoo.in) Satish Chander Narula

Post Graduate Institute of Dental Sciences, Rohtak, Haryana, India.

(e-mail: scnarula@gmail.com)

*Corresponding Author

\section{INTRODUCTION}

Periodontal plastic surgeries comprising of various procedures is directed at correction or elimination of the developmental and anatomic deformities of the gingiva and the alveolar mucosa [1]. Interdental papilla loss is one such problem. Loss of interdental papilla gives rise to a multitude of problems such as food retention, problems with phonetics and an unaesthetic look [2]. Interdental papilla reconstruction is one of the most challenging tasks due to lack of adequate blood supply is a major obstacle in achieving the desired outcome of any attempts at regeneration.

Various surgical and non-surgical procedures have been enumerated in literature for the reconstruction of interdental papilla. The surgical techniques have been aimed at recontouring and reconstructing the deficient interdental papilla which include the pedicle graft procedure [3], envelop type flap prepared for placing a connective tissue graft [4]-[7]or platelet rich fibrin at the recipient site is [8], [9]. Case reports and case series have been done utilizing the connective tissue graft with encouraging results in the form of complete or partial interdental papilla fill [4]-[7].

As evidenced by the literature, PRF has a potential role in regeneration of the periodontium and tissue engineering. PRF acts as a vehicle in carrying cells that participate in tissue regeneration and also appears to have a sustained release of growth factors between the period from 1 to 4 weeks [10]. Studies have concluded that PRF provides an increment in gingival width and thickness (gingival biotype) [11]. Few case reports have utilized PRF in reconstruction of the lost interdental papilla. Furthermore, use of PRF, precludes the need for a second surgical site and therefore, the associated complications. On comprehensive search of literature, only two studies [12], [13] till date have been evident comparing the effect of subepithelial connective tissue graft and PRF for papilla reconstruction. Therefore, due to paucity of literature and strengthening the existing scientific evidence, the present study was conducted to compare platelet rich fibrin and subepithelial connective tissue graft in interdental papilla reconstruction. 


\section{MATERIALS AND METHOD}

\section{A. Study Design}

The present prospective, analytical, single blinded, randomized clinical trial (ClinicalTrials.gov: NCT03899051) was conducted in the Department of Periodontology, Post Graduate Institute of Dental Sciences, Rohtak. The protocol was approved by the Institutional Review Board, Pandit Bhagwat Dayal Sharma University of Health Sciences, Rohtak (PGIDS/IEC/2018/5). The study period was from February 2019 to April 2020.

\section{B. Sample Size Calculation}

Based on data from the previous study[14], a difference of $1 \mathrm{~mm}$ for gain in papilla height in between the groups (standard deviation: $1.0 \mathrm{~mm}$; significance level alpha: 0.05, power: 0.8 ) resulted in a sample size of 16 patients. A total of 18 patients per group were recruited to compensate for possible dropout.

\section{Study Population}

A total of 90 patients were screened amongst which 36 individuals were included in the study based on inclusion and exclusion criteria and received phase I therapy. The patients were recruited from the outpatient department of Department of Periodontology, Post Graduate Institute of Dental Sciences, Rohtak. Written and verbal consent was sought from the participants who were willing to participate in the study. By using random allocation software, the participants were further divided, randomly, into two groups- test group and control group with 18 participants in each. Block randomization of 4 and 6 by random allocation software system.

The inclusion criteria were: patients within the age range of 18-55 years and who were systemically healthy, patients having class I and class II papillary recession according to Nordland and Tarnow's classification [15] in the maxillary anterior region, patients who have undergone complete etiological periodontal therapy (full mouth scaling and root planing) with Plaque index (Silness \& Loe) $<1$, gingival index (Loe \& Silness) <1. Exclusion criteria were:patients with systemic disease or on medications that affect the outcome of periodontal therapy, presence of open contacts or crowding, pregnancy and lactation, active periodontal disease, smokers and tobacco users.

\section{Inter Examiner Reproducibility}

All clinical periodontal examinations were done by two calibrated investigators who were blinded (NT, ST) to preclude any inter examiner reproducibility. Calibration of the examiners was performed by duplicating CPID and PPD measurements on 10 randomly selected individuals prior to initiation of the study. Calibration exercise was done until $\geq 90 \%$ reproducibility in CPID and PPD measurement was achieved.

\section{E. Surgical Procedure}

The surgical procedure in all the patients were performed by the same periodontist (IG). Han \& Takei technique [16] was performed to generate a pouch in the interdental papilla to be reconstructed.
Platelet rich fibrin (PRF) was prepared according to the protocol given by Choukron et al. [17] and subepithelial connective tissue graft was procured from the palate in the maxillary premolars/first molar region. Both were trimmed to the required size was trimmed and were placed on the recipient bed (Fig. 1 and 2). Suturing was done with a 5-0 vicryl suture. (Ethicon, Ethicon Vicryl \#5-0 absorbable braided suture).

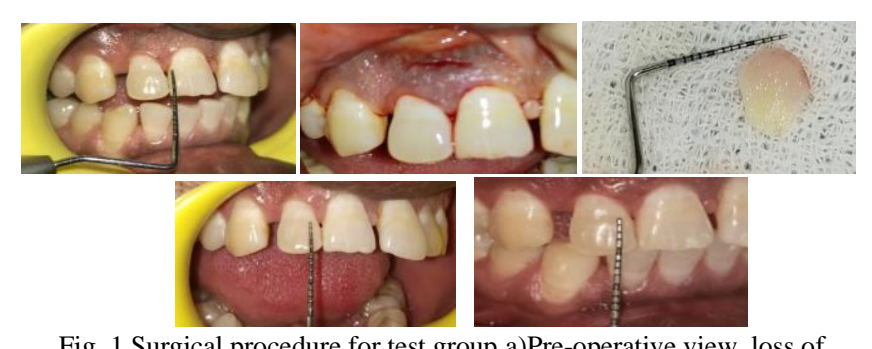

Fig. 1.Surgical procedure for test group a)Pre-operative view, loss of papillary height $=1 \mathrm{~mm}$ b)Semilunar incision given c)PRF membrane e) 3 month post operative view. f) Complete reconstruction of interdental papilla 6 month post-operatively.

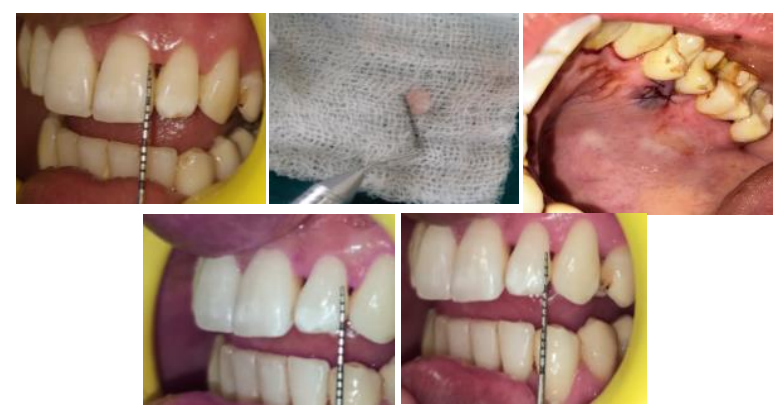

Fig. 2. Surgical procedure for control group a) Pre-operative view, loss of papillary height $=2 \mathrm{~mm}$ b)Subepithelial connective tissue graft harvested from palate c)Donor site d) 3 month post operative view e) 6 month post operative view showing gain of $1 \mathrm{~mm}$ in papillary height.

\section{F. Primary and Secondary Outcome Variables}

Distance from the contact point to the tip of the interdental papilla (CPID), Width of keratinized gingiva (WKG). Healing Index(HI) [18] were considered as primary outcome variables. Plaque Index (PI), Gingival Index (GI),Pocket probing depth(PPD), Papillary Bleeding Index (PBI) were the secondary outcome variables. All these parameters were evaluated at baseline, 3 months, and 6 months. Healing Index(HI) [18] was recorded at 1 week, 2 weeks and 3 weeks interval. For statistical analysis PPD, PI, GI at the interproximal site was taken as one unit and these parameters were measured at four sites of papilla i.e., mesiobuccal, distobuccal, mesiopalatal and distopalatal.

\section{G. Postoperative Care}

Post-operative instructions and Antibiotic (Amoxycillin $500 \mathrm{mg}$ Mankind Pharmaceuticals 8 hourly for 5 days) along with analgesic (Ibuprofen $400 \mathrm{mg}$ Abott India 8 hourly for three days) were prescribed in all the patients. All the subjects were instructed to rinse with $0.2 \%$ chlorhexidine gluconate twice daily for 2 weeks. Sutures were removed 10 days postoperatively.

\section{H. Statistical Analysis}

Processing of recorded data was done by standard statistical analysis using IBM SPSS 25 software. The normality of distribution of data was examined by Shapiro 
Wilk test. The data was non normally distributed. Intra group comparison was done using Wilcoxon signed rank test between different time points and inter group comparison was done by Mann Whitney U test.

\section{RESULTS}

Of the 36 patients recruited 16 patients from test group and 16 patients from the control group were completed the treatment protocol. Two patients were dropout from each group and a total of 32 patients were analyzed. (Fig. 3). Healing was uneventful, no break in suture, no dehiscence in incision line, no post-operative swelling was noted. Patient also did not report any pain or discomfort. Intragroup comparison of clinical parameters (Table II) revealed a statistically significant $(\mathrm{p} \leq 0.05)$ decrease in CPID and increase in WKG in both the groups, at the end of 6 months. Intergroup comparison (Table III) yielded a statistically significant improvement in gain in papillary height in terms of CPID and WKG in control group (39.32\%) in comparison with the test group of $(14.9 \%)$. In the test group, the improvement in plaque and gingival indices at 6 months, were found to be statistically significant when compared with baseline while no significant change was seen in the control group.

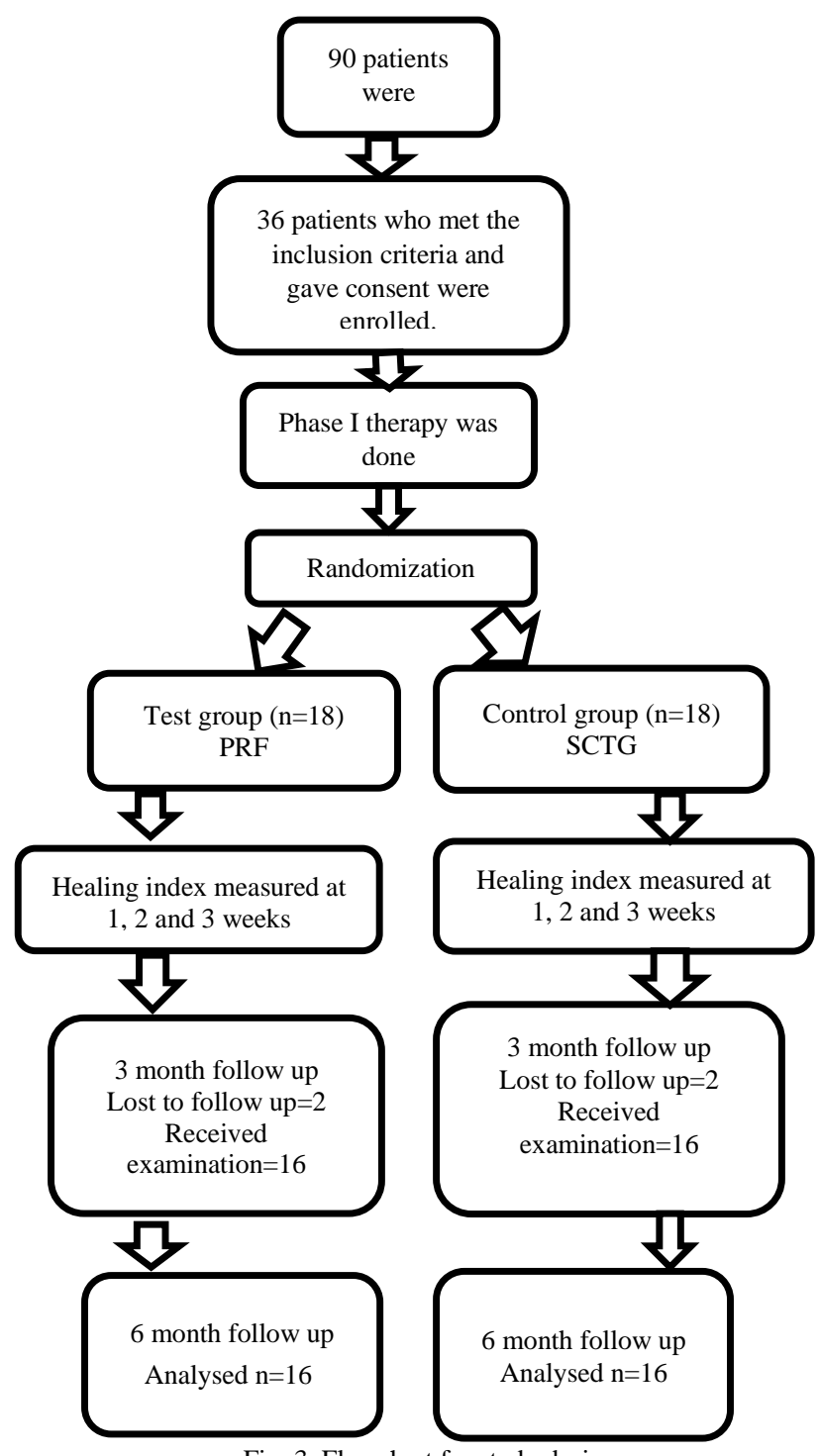

Fig. 3. Flowchart for study design.
TABLE I: DEMOGRAPHY OF THE STUDY POPULATION AND COMPARISON OF BASELINE PARAMETERS OF BOTH GROUPS

\begin{tabular}{cccc}
\hline $\begin{array}{c}\text { Parameters } \\
(\mathrm{n}=32)\end{array}$ & $\begin{array}{c}\text { Control } \\
\text { Group (CG) } \\
\text { Connective } \\
\text { Tissue(n=16) }\end{array}$ & $\begin{array}{c}\text { Test Group } \\
\text { (TG) } \\
\text { Platelet Rich } \\
\text { Fibrin (n=16) }\end{array}$ & P-value \\
\hline Age(yrs) & & & \\
(X \pm S.D.; & $37.94 \pm 8.48$ & $35 \pm 8.74$ & 0.776 \\
range) & $(22-55)$ & $(18-48)$ & \\
36.47 \pm 8.60 & & & \\
(18-55) & & & \\
Gender [n (\%)] & & $6(37.5 \%)$ & 0.714 \\
Female & $5(31.3 \%)$ & $10(62.5 \%)$ & \\
11(34.4) & $11(68.8 \%)$ & & \\
Male 21(65.6) & & & \\
PI $^{*}$ & $0.17 \pm 0.18$ & $0.27 \pm 0.21$ & 0.254 \\
GI $^{*}$ & $0.12 \pm 0.17$ & $0.22 \pm 0.26$ & 0.323 \\
PPD $^{*}$ & $2.22 \pm 0.27$ & $2.15 \pm 0.31$ & 0.402 \\
PBI $^{*}$ & $0.38 \pm 0.50$ & $0.25 \pm 0.45$ & 0.564 \\
CPID $^{*}$ & $2.06 \pm 0.57$ & $1.69 \pm 0.70$ & 0.138 \\
WKG $^{*}$ & $6.50 \pm 1.09$ & $7.31 \pm 1.40$ & 0.094 \\
\hline
\end{tabular}

Notes. Data is displayed as mean $\pm \mathrm{SD}, * \mathrm{P}$ value $\leq 0.05$ indicates significance, ** Wilcoxon signed rank test., Abbreviations: PI:plaque index GI: gingival index PPD: probing pocket depth PBI:papillary bleeding index CPID:contact point to interdental papilla distance WKG:width of keratinized gingiva.

TABLE II: INTRAGROUP COMPARISON OF PARAMETERS IN CONTROL AND TEST GROUPS

\begin{tabular}{|c|c|c|c|c|}
\hline & & & & \\
\hline Parameters & Group & Baseline & 3 months & p-value \\
\hline \multirow{2}{*}{$\mathrm{PI}^{\ddagger}$} & Control & $0.17 \pm 0.18$ & $0.23 \pm 0.33$ & 0.175 \\
\hline & Test & $0.27 \pm 0.21$ & $0.21 \pm 0.25$ & 0.102 \\
\hline \multirow{2}{*}{$\mathrm{GI}^{\ddagger}$} & Control & $0.12 \pm 0.17$ & $0.32 \pm 0.25$ & 0.551 \\
\hline & Test & $0.22 \pm 0.26$ & $0.17 \pm 0.25$ & 0.359 \\
\hline \multirow{2}{*}{ PPD } & Control & $0.12 \pm 0.17$ & $0.32 \pm 0.25$ & 0.713 \\
\hline & Test & $2.15 \pm 0.31$ & $2.15 \pm 0.31$ & 0.438 \\
\hline \multirow{2}{*}{$\mathrm{PBI}^{\ddagger}$} & Control & $0.38 \pm 0.50$ & $0.31 \pm 0.48$ & 0.739 \\
\hline & Test & $0.25 \pm 0.45$ & $0.19 \pm 0.40$ & 0.705 \\
\hline \multirow{2}{*}{$\mathrm{CPID}^{\ddagger}$} & Control & $2.06 \pm 0.57$ & $1.44 \pm 0.73$ & $0.004^{\dagger}$ \\
\hline & Test & $1.69 \pm 0.70$ & $1.50 \pm 0.73$ & 0.083 \\
\hline \multirow{2}{*}{$\mathrm{WKG}^{\ddagger}$} & Control & $6.50 \pm 1.09$ & $7.13 \pm 1.09$ & $0.004^{\dagger}$ \\
\hline & Test & $7.31 \pm 1.40$ & $7.50 \pm 1.31$ & 0.083 \\
\hline Parameters & & 3 months & 6 months & p-value \\
\hline \multirow{2}{*}{$\mathrm{PI}^{\ddagger}$} & Control & $0.23 \pm 0.33$ & $0.28 \pm 0.19$ & 0.719 \\
\hline & Test & $0.21 \pm 0.25$ & $0.13 \pm 0.12$ & 0.256 \\
\hline \multirow{2}{*}{$\mathrm{GI}^{\ddagger}$} & Control & $0.32 \pm 0.25$ & $0.24 \pm 0.31$ & 0.837 \\
\hline & Test & $0.17 \pm 0.25$ & $0.06 \pm 0.12$ & 0.101 \\
\hline \multirow{2}{*}{ PPD } & Control & $0.32 \pm 0.25$ & $2.17 \pm 0.24$ & 0.595 \\
\hline & Test & $2.09 \pm 0.29$ & $2.17 \pm 0.31$ & 0.272 \\
\hline \multirow{2}{*}{$\mathrm{PBI}^{+}$} & Control & $0.31 \pm 0.48$ & $0.25 \pm 0.45$ & 0.655 \\
\hline & Test & $0.19 \pm 0.40$ & $0.06 \pm 0.25$ & 0.157 \\
\hline \multirow{2}{*}{$\mathrm{CPID}^{*}$} & Control & $1.44 \pm 0.73$ & $1.25 \pm 0.78$ & 0.083 \\
\hline & Test & $1.50 \pm 0.73$ & $1.44 \pm 0.81$ & 0.564 \\
\hline \multirow{2}{*}{$\mathrm{WKG}^{\ddagger}$} & Control & $7.13 \pm 1.09$ & $7.31 \pm 1.08$ & 0.083 \\
\hline & Test & $7.50 \pm 1.31$ & $7.56 \pm 1.41$ & 0.564 \\
\hline Parameters & & Baseline & 6 months & p-value \\
\hline \multirow{2}{*}{$\mathrm{PI}^{\ddagger}$} & Control & $0.17 \pm 0.18$ & $0.28 \pm 0.19$ & 0.289 \\
\hline & Test & $0.27 \pm 0.21$ & $0.13 \pm 0.12$ & $0.008^{\dagger}$ \\
\hline \multirow{2}{*}{$\mathrm{GI}^{*}$} & Control & $0.12 \pm 0.17$ & $0.24 \pm 0.31$ & 0.229 \\
\hline & Test & $0.22 \pm 0.26$ & $0.06 \pm 0.12$ & $0.031^{\dagger}$ \\
\hline \multirow{2}{*}{$\mathrm{PPD}^{\ddagger}$} & Control & $0.12 \pm 0.17$ & $2.17 \pm 0.24$ & 0.380 \\
\hline & Test & $2.15 \pm 0.31$ & $2.17 \pm 0.31$ & 0.794 \\
\hline \multirow{2}{*}{$\mathrm{PBI}^{\ddagger}$} & Control & $0.38 \pm 0.50$ & $0.25 \pm 0.45$ & 0.527 \\
\hline & Test & $0.25 \pm 0.45$ & $0.06 \pm 0.25$ & 0.180 \\
\hline \multirow{2}{*}{$\mathrm{CPID}^{\ddagger}$} & Control & $2.06 \pm 0.57$ & $1.25 \pm 0.78$ & 0.006 \\
\hline & Test & $1.69 \pm 0.70$ & $1.44 \pm 0.81$ & $0.046^{\dagger}$ \\
\hline \multirow{2}{*}{$\mathrm{WKG}^{\ddagger}$} & Control & $6.50 \pm 1.09$ & $7.31 \pm 1.08$ & 0.006 \\
\hline & Test & $7.31 \pm 1.40$ & $7.56 \pm 1.41$ & $0.046^{\dagger}$ \\
\hline Parameters & & Baseline & Post surgery & p-value \\
\hline \multirow{2}{*}{ CPID } & Control & $2.06 \pm 0.57$ & $1.31 \pm 0.70$ & $0.001^{\dagger}$ \\
\hline & Test & $1.69 \pm 0.70$ & $0.94 \pm 0.57$ & $0.001^{\dagger}$ \\
\hline Parameters & & Post surgery & 3 months & p-value \\
\hline \multirow{2}{*}{ CPID } & Control & $1.31 \pm 0.70$ & $1.44 \pm 0.73$ & 0.414 \\
\hline & Test & $0.94 \pm 0.57$ & $1.50 \pm 0.73$ & $0.003^{\dagger}$ \\
\hline Parameters & & Post surgery & 6 months & p-value \\
\hline \multirow{2}{*}{$\mathrm{CPID}^{\ddagger}$} & & $1.31 \pm 0.70$ & $1.25 \pm 0.78$ & $0.003^{\dagger}$ \\
\hline & Test & $0.94 \pm 0.57$ & $1.44 \pm 0.81$ & $0.005^{\dagger}$ \\
\hline
\end{tabular}

**Wilcoxon signed rank test. 
TABLE III : INTERGROUP COMPARISON OF IMPROVEMENTS $(\Delta)$ IN PARAMETERS

\begin{tabular}{|c|c|c|c|}
\hline $\begin{array}{c}\text { Parameters at } \\
\text { baseline at } 3 \text { months }\end{array}$ & Control Group & Test Group & P-value \\
\hline $\mathrm{PI}^{*}$ & $-0.16 \pm 0.36$ & $0.06 \pm 0.15$ & 0.118 \\
\hline $\mathrm{GI}^{*}$ & $-0.11 \pm 0.43$ & $0.04 \pm 0.20$ & 0.492 \\
\hline PPD* & $0.02 \pm 0.36$ & $0.06 \pm 0.26$ & 0.182 \\
\hline PBI* & $0.06 \pm 0.77$ & $0.06 \pm 0.68$ & 0.984 \\
\hline CPID* & $\begin{array}{c}0.63 \pm 0.62 \\
(30.1 \%)\end{array}$ & $\begin{array}{c}0.19 \pm 0.40 \\
(11.24 \%)\end{array}$ & 0.027 \\
\hline $\mathrm{WKG}^{*}$ & $-0.63 \pm 0.62$ & $-0.19 \pm 0.40$ & 0.027 \\
\hline $\begin{array}{c}\text { Parameters at } 3 \\
\text { months and } 6 \\
\text { months }\end{array}$ & Control Group & Test Group & P-value \\
\hline $\mathrm{PI}^{*}$ & $-0.01 \pm 0.32$ & $0.08 \pm 0.23$ & 0.302 \\
\hline $\mathrm{GI}^{*}$ & $-0.01 \pm 0.32$ & $0.11 \pm 0.27$ & 0.497 \\
\hline PPD* & $0.03 \pm 0.29$ & $-0.08 \pm 0.27$ & 0.260 \\
\hline PBI** & $0.06 \pm 0.57$ & $0.13 \pm 0.34$ & 0.984 \\
\hline CPID * & $0.18 \pm 0.83$ & $0.06 \pm 0.44$ & 0.420 \\
\hline $\mathrm{WKG}^{*}$ & $-0.19 \pm 0.40$ & $-0.06 \pm 0.44$ & 0.420 \\
\hline $\begin{array}{c}\text { Parameters at } \\
\text { baseline at } 6 \text { months }\end{array}$ & Control Group & Test Group & P-value \\
\hline $\mathrm{PI}^{*}$ & $-0.11 \pm 0.28$ & $0.14 \pm 0.20$ & 0.022 \\
\hline GI* & $-0.12 \pm 0.42$ & $0.16 \pm 0.29$ & 0.173 \\
\hline PPD* & $0.05 \pm 0.23$ & $-0.02 \pm 0.29$ & 0.400 \\
\hline PBI* & $0.13 \pm 0.81$ & $0.19 \pm 0.54$ & 0.900 \\
\hline CPID* & $\begin{array}{c}0.81 \pm 0.83 \\
(39.32 \%)\end{array}$ & $\begin{array}{c}0.25 \pm 0.45 \\
(14.79 \%)\end{array}$ & 0.039 \\
\hline WKG* & $-0.81 \pm 0.83$ & $-0.25 \pm 0.45$ & 0.039 \\
\hline
\end{tabular}

*Mann-Whitney u analysis.

\section{DISCUSSION}

It has been established beyond doubt that interdental papilla has a key role in aesthetics. Several factors have been cited for its loss [19], [20]. Absence of the papilla leads to the formation of black triangles and thus leading to aesthetic impairment. Therefore, its preservation [21] as well as reconstruction in cases of its absence, is of utmost importance. The reconstruction of interdental papilla has always been a daunting task for the clinician owing to its unique anatomy, morphology and limited blood supply [16] and is therefore a relatively difficult area of research.

Various procedures have been put forth in the form of case reports and case series. Autogenous substances such as subepithelial connective tissue graft and platelet rich fibrin, attributing to their property of histoconduction, act as space maintainers [21]. Owing to the dearth of literature in terms of strong scientific evidence, the present randomized controlled trial was done to compare the interdental papilla regeneration using subepithelial connective tissue graft and PRF using Han \& Takei technique [16].

Participants having vertical distance $\leq 7 \mathrm{~mm}$ from contact point to alveolar crest radiographically were included as this distance correlates with mild to moderate papillary recessions [20]. The data at baseline was homogenous. Participants with open contacts were excluded as it would be difficult to measure the vertical distance due to lack of a reference point. Smokers were excluded from the study since the constituents of tobacco, primarily nicotine, have detrimental effects on vasculature and wound healing by diminishing the function of fibroblast.

In the present study the mean papillary height and width of keratinized gingiva consistently increased on intragroup comparison in connective tissue group from baseline to 3 and 6 months follow up. These results are in accordance with the study done by Sharma et al. [5] where on papilla reconstruction using connective tissue graft, the papillary height and width of keratinized gingiva increased significantly from baseline to 3 and 6 months follow up. Another similar study conducted by Kaushik et al. [4] also reported a significant improvement in the height of papilla and keratinized gingiva from baseline to 1 month, however, in contrast to the present study, the results obtained remained stable at 3 and 6 months follow up.

In the PRF group, gain in height of interdental papilla was observed in the present study from baseline to 6 months, whereas in the study by Ahila et al. [9] a gain in both papillary height and width of keratinized gingiva was recorded from baseline to 3 months and also from 3 to 6 months. However, the vertical dimensions from the contact point to the papilla tip was more in the study by Ahila et al. $(4.28 \pm 0.458 \mathrm{~mm})$ as compared to the present study $(1.69 \pm 0.70 \mathrm{~mm})$. However, the abovementioned study is in the form of case series and hence the interpretation of the results should be done prudently.

On intergroup comparison, it was found that there was more improvement in the height of papilla and the keratinized gingiva in control group in comparison with test group and the improvement was statistically significant at 3 months from baseline and at 6 months from baseline in the present study. The results obtained at 3 months are in accordance with the study conducted by Sharma et al. [13], where they also found better improvement in the connective tissue group. In contrast, Singh et al. [12], in a similar study concluded that although there was a statistically significant gain in the height of papilla in both the groups, intergroup comparison yielded a non-significant difference between the two groups. However, the duration of the abovementioned [12], [13] studies was 3 months.

Karring et al. [22] through an animal study determined that the gingival connective tissue inherently contains a message that brings about changes in the epithelial differentiation. The graft was harvested from the palate as the palatal epithelium is orthokeratinized therefore, the subepithelial connective tissue graft placed could have been responsible for the gain in interdental papilla height. Connective tissue graft acts as a bridge between the underlying periosteum and the lamina propria on the outer surface. It is a firm tissue comprising of various nerves, glands, and adipose tissue. Connective tissue being dense is more resistant to postoperative shrinkage as compared to the delicate PRF membrane[23]. These results are in accordance with a randomized controlled clinical trial by Ustaoglu et al. [24], where they compared connective tissue graft with PRF for thickening of peri implant soft tissue and keratinized mucosa width. They concluded that connective tissue showed a highly significant gain in the width of keratinized gingiva and peri-implant soft tissue thickness as compared to PRF.

Statistical analysis was also done to observe the coronal shift of the gingivo-papillary unit post suturing. Similar gain in mean papillary height post suturing was achieved in both the groups. It was observed the papilla height was gained further in connective tissue graft group post 6 months as compared to post suturing while in the PRF group, the achieved papilla height post suturing was partially lost on 3 
and 6 months follow ups. Other parameters were also assessed which may affect the final outcome of the surgical procedure. On intragroup comparison, a slight deterioration in the plaque levels was noted in the control group, however, this was statistically insignificant. The increase in the plaque index score could be attributed to the presence of two surgical sites which increased patient's apprehension to brush. In contrast to the findings of the control group, a statistically significant decrease in the plaque index scores was noted in the test group. Intergroup comparison of the plaque scores at baseline and 6 months revealed a statistically significant improvement in the plaque scores of test group and remained in the range corresponding to good oral hygiene.

Similar results as of control group were reported in a study conducted by Shruthi S et al. [25] comparing two techniques of papilla reconstruction, where no statistically significant difference was noted on subsequent follow ups. The results were in contrast to a study conducted by Kaushik et al. [4] where a statistically significant improvement was noted in plaque scores on subsequent follow ups.

A statistically significant improvement was seen in gingival inflammation in the test group at 6 months. However, in the control group, it remained similar to the baseline levels. On intergroup comparison, no significant difference was found in between the groups. The change in scores of the mean papillary bleeding index on 3 and 6 month follow up were statistically insignificant in both the groups. This could be attributed to meticulous plaque control at each follow up.

At 3 and 6 months, no statistically significant difference was found in the pocket depth in both the groups. These results are in agreement with those obtained by Shruthi S. et al. [25] where they compared two techniques of papilla reconstruction. However, the results are in contrast to those found in a study by Sharma et al. [5] in which reconstruction was done using connective tissue graft and a moderate increase in pocket depth was citing coronal displacement of the gingiva-papillary unit as the reason for this increase. In the present study as the width of keratinized gingiva increased despite of no increase in pocket depth, this implies periodontal regeneration might have taken place, however, no histologic evaluation was done so as to ascertain the type of tissue formed.

Wound Healing assessed by Healing Index up to 3 weeks in terms of tissue color, presence or absence of granulation tissue, response to palpation, suppuration, epithelialisation of incision margin and exposure of the graft, in both the groups. On intergroup comparison, comparable healing was achieved in both the groups. Uneventful Healing was also observed at the donor site.

Han \& Takei [16] procedure offers the advantage of absence of vertical incisions, thus, without jeopardizing the vascular supply of the interdental area. This technique uses a type of pedicle grafting which has been proved to yield superior results as compared to a free gingival graft [26].The coronal position is maintained by the placement of subepithelial connective tissue graft or the PRF membrane put through the semilunar incision [16]. Atraumatic handling of tissue by using ophthalmic tunnel blade (Zymeck keratome $2.8 \mathrm{~mm} \mathrm{SB} \mathrm{Up} \mathrm{S)} \mathrm{results} \mathrm{in} \mathrm{less} \mathrm{postoperative}$ swelling and preservation of the blood supply of the area. Suspensory sutures were given. These suture aids in maintenance of the papilla in its new position as the surrounding musculature possess a tendency to pull the papilla to its original position. Also, as healing takes place at the surgical site, wound tension can eventually result in generation of forces to the graft and adjacent tissues which could be detrimental to the results obtained [7].

PRF has the ability to release various cytokines and growth factors such as TGF- $\beta 1$ PDGF, IL-1,4,6, EGF. These factors help in tissue healing as well as it's regeneration [27]. Its three-dimensional structure entraps various cytokines thus playing a direct role in angiogenesis induction and supporting capillary formation. The gelation of PRF is relatively slow, thereby having a large number of crossed alpha-chains which brings about optimal fibroblastic movement, subsequently guiding wound coverage. It also affects the metabolism of epithelial cells [27]. Therefore, PRF allows for an earlier wound healing and due to all the aforementioned properties, it could result in improvement in gingival phenotype. Low cost, absence of a second surgical site, simple procedure for the retrieval of PRF add to its many advantages. A study done by Padma et al. [28] in relation to treatment of gingival recession has revealed that PRF leads to an increase in clinical attachment levels and WKG. Studies conducted by Keceli et al. [29] reported a definite improvement in gingival phenotype. So, considering the above-mentioned merits of PRF, it was hypothesized that it could prove beneficial in reconstruction of the interdental papilla. Few studies used PRF in reconstruction of interdental papilla and were in the form of case report and case series, although PRF showed a definite improvement [8], [9].

PRF owns a disadvantage of degrading early, subsequently leading to a decline in the biomolecules released from it [30]. Also, as a consequence initial stabilization of the periodontal tissues is affected. This is in contrast to grafts such as the connective tissue grafts, where no such phenomena are seen and thus, these are hailed as the gold standard to correct gingival recessions. The result of current study also analysed and demonstrated more promising results with connective tissue graft.

A small sample size and a short follow up period are the limitations of the study. Lack of histologic evaluation was another drawback of this study. The interdental area has the tendency to retain plaque which subsequently leads to inflammation of the interdental papilla.Focus on prevention should be the priority as the results attained are seldom $100 \%$.

Within the confines of the present study, it can be concluded that subepithelial connective tissue graft is better as compared to platelet rich fibrin for interdental papilla reconstruction. However, PRF has too shown promising results and future research is paramount so that it's properties could be utilized in a more beneficial way. The results obtained from the current study need to be verified through multicentre trials and longer follow up periods. 


\section{REFERENCES}

[1] P. D. Miller Jr and E. P. Allen, "The development of periodontal plastic surgery," Periodontol. 2000, vol. 11, no. 1, pp. 7-17, 1996.

[2] J. LINDHE, "Mucogingival therapy-periodontal plastic surgery," Clin. Periodontlogy Implant Dent., pp. 588-592, 2003.

[3] J. R. Beagle, "Surgical reconstruction of the interdental papilla: Case report.," Int. J. Periodontics Restorative Dent., vol. 12, no. 2, 1992.

[4] A. Kaushik et al., "Clinical evaluation of papilla reconstruction using subepithelial connective tissue graft," J. Clin. Diagn. Res. JCDR, vol. 8, no. 9, p. ZC77, 2014.

[5] E. Sharma, A. Sharma, and K. Singh, "The role of subepithelial connective tissue graft for reconstruction of interdental papilla: Clinical study,” Singapore Dent. J., vol. 38, pp. 27-38, 2017.

[6] R. Azzi, H. H. Takei, D. Etienne, and F. A. Carranza, "Root coverage and papilla reconstruction using autogenous osseous and connective tissue grafts.," Int. J. Periodontics Restorative Dent., vol. 21, no. 2, 2001.

[7] W. P. Nordland and H. S. Sandhu, "Microsurgical technique for augmentation of the interdental papilla: three case reports.," Int. J. Periodontics Restorative Dent., vol. 28, no. 6, 2008.

[8] L. T. Arunachalam, S. Merugu, and U. Sudhakar, "A novel surgical procedure for papilla reconstruction using platelet rich fibrin," Contemp. Clin. Dent., vol. 3, no. 4, p. 467, 2012.

[9] E. Ahila, R. S. Kumar, V. K. Reddy, B. Pratebha, M. Jananni, and V. Priyadharshini, "Augmentation of interdental papilla with platelet-rich fibrin," Contemp. Clin. Dent., vol. 9, no. 2, p. 213, 2018.

[10] D. M. Dohan et al., "Platelet-rich fibrin (PRF): a second-generation platelet concentrate. Part I: technological concepts and evolution," Oral Surg. Oral Med. Oral Pathol. Oral Radiol. Endodontology, vol. 101, no. 3, pp. e37-e44, 2006.

[11] U. P. Verma, R. K. Yadav, M. Dixit, and A. Gupta, "Platelet-rich fibrin: a paradigm in periodontal therapy-a systematic review," J. Int. Soc. Prev. Community Dent., vol. 7, no. 5, p. 227, 2017.

[12] D. Singh, R. Jhingran, V. K. Bains, R. Madan, and R. Srivastava, "Efficacy of Platelet-rich Fibrin in Interdental Papilla Reconstruction as Compared to Connective Tissue Using Microsurgical Approach," Contemp. Clin. Dent., vol. 10, no. 4, pp. 643-651, Dec. 2019, doi: 10.4103/ccd.ccd_936_18.

[13] P. Sharma, S. Vaish, N. Sharma, V. Sekhar, M. Achom, and F. Khan, "Comparative evaluation of efficacy of subepithelial connective tissue graft versus platelet-rich fibrin membrane in surgical reconstruction of interdental papillae using Han and Takie technique: A randomized controlled clinical trial," J. Indian Soc. Periodontol., vol. 24, no. 6, pp. 547-553, Dec. 2020, doi: 10.4103/jisp.jisp_125_20.

[14] W. Becker, I. Gabitov, M. Stepanov, J. Kois, A. Smidt, and B. E. Becker, "Minimally invasive treatment for papillae deficiencies in the esthetic zone: a pilot study," Clin. Implant Dent. Relat. Res., vol. 12, no. 1 , pp. $1-8,2010$.

[15] W. P. Nordland and D. P. Tarnow, "A classification system for loss of papillary height,” J. Periodontol., vol. 69, no. 10, pp. 1124-1126, 1998.

[16] T. J. Han and H. H. Takei, "Progress in gingival papilla reconstruction," Periodontol. 2000, vol. 11, no. 1, pp. 65-68, 1996.

[17] D. M. Dohan et al., "Platelet-rich fibrin (PRF): a second-generation platelet concentrate. Part II: platelet-related biologic features," Oral Surg. Oral Med. Oral Pathol. Oral Radiol. Endodontology, vol. 101, no. 3, pp. e45-e50, 2006.

[18] R. G. Landry, "Effectiveness of Benzydamine HC1 in the Treatment of Periodontal Post-surgical Patients," PhD Thesis, Faculty of Dentistry, University of Toronto, 1985.

[19] J. Carnio and A. T. Carnio, "Papilla reconstruction: Interdisciplinary consideration for clinical success," J. Esthet. Restor. Dent., vol. 30, no. 6, pp. 484-491, 2018.

[20] D. P. Tarnow, A. W. Magner, and P. Fletcher, "The effect of the distance from the contact point to the crest of bone on the presence or absence of the interproximal dental papilla," J. Periodontol., vol. 63, no. 12, pp. 995-996, 1992.

[21] G. Ustaoğlu, E. Ercan, and M. Tunali, "The role of titanium-prepared platelet-rich fibrin in palatal mucosal wound healing and histoconduction," Acta Odontol. Scand., vol. 74, no. 7, pp. 558-564, 2016.

[22] T. Karring, N. P. Lang, and H. Löe, "The role of gingival connective tissue in determining epithelial differentiation," J. Periodontal Res., vol. 10 , no. 1, pp. 1-11, 1975 .

[23] O. Zuhr, D. Bäumer, and M. Hürzeler, "The addition of soft tissue replacement grafts in plastic periodontal and implant surgery: critical elements in design and execution," J. Clin. Periodontol., vol. 41 Suppl 15, pp. S123-142, Apr. 2014, doi: 10.1111/jcpe.12185.
[24] G. Ustaoglu, T. Paksoy, and K. C. Gumus, "Titanium-Prepared Platelet-Rich Fibrin Versus Connective Tissue Graft on Peri-Implant Soft Tissue Thickening and Keratinized Mucosa Width: A Randomized, Controlled Trial,” J. Oral Maxillofac. Surg., 2020.

[25] S. Shruthi, S. K. Gujjari, and K. P. Mallya, "Comparison of two surgical techniques for the reconstruction of interdental papilla," $J$. Interdiscip. Dent., vol. 5, no. 1, p. 17, 2015.

[26] H. E. Grupe and R. F. Warren Jr, "Repair of gingival defects by a sliding flap operation," J. Periodontol., vol. 27, no. 2, pp. 92-95, 1956.

[27] J. Choukroun et al., "Platelet-rich fibrin (PRF): a second-generation platelet concentrate. Part IV: clinical effects on tissue healing," Oral Surg. Oral Med. Oral Pathol. Oral Radiol. Endodontology, vol. 101, no. 3, pp. e56-e60, 2006.

[28] R. Padma, A. Shilpa, P. A. Kumar, M. Nagasri, C. Kumar, and A. Sreedhar, "A split mouth randomized controlled study to evaluate the adjunctive effect of platelet-rich fibrin to coronally advanced flap in Miller's class-I and II recession defects," J. Indian Soc. Periodontol. vol. 17, no. 5, p. 631, 2013.

[29] H. G. Keceli, G. Kamak, E. O. Erdemir, M. S. Evginer, and A. Dolgun, "The adjunctive effect of Platelet-Rich Fibrin to Connective Tissue Graft in the treatment of buccal recession defects: results of a randomized, parallel-group controlled trial," J. Periodontol., vol. 86, no. 11, pp. 1221-1230, 2015.

[30] D. M. Dohan Ehrenfest, G. M. de Peppo, P. Doglioli, and G. Sammartino, "Slow release of growth factors and thrombospondin-1 in Choukroun's platelet-rich fibrin (PRF): a gold standard to achieve for all surgical platelet concentrates technologies," Growth Factors Chur Switz., vol. 27, no. 1, pp. 63-69, Feb. 2009, doi: 10.1080/08977190802636713 